\title{
Reactions of Diacetylene Radical Cation with Ethylene
}

\author{
Daniel J. Goebbert, Xinping Liu, ${ }^{*}$ and Paul G. Wenthold \\ Department of Chemistry, Purdue University, West Lafayette, Indiana, USA
}

\begin{abstract}
Ion-molecule reactions and energy-resolved mass spectrometry have been used to determine the structures of the products formed in the reaction of diacetylene radical cation with ethylene in a flowing afterglow-triple quadrupole instrument. The structure of the adduct ion, $\mathrm{C}_{6} \mathrm{H}_{6}^{+}$, has been determined to be that of singly ionized benzene. The reaction thus presents a first example of the ability of diacetylene radical cation to undergo an aromatic ring forming reaction. The other products formed in the reaction are $m / z 52, \mathrm{C}_{4} \mathrm{H}_{4}^{++}$, and $\mathrm{m} / \mathrm{z} 39, \mathrm{C}_{3} \mathrm{H}_{3}^{+}$. Isotopic labeling studies show that $\mathrm{C}_{4} \mathrm{H}_{4}^{++}$and $\mathrm{C}_{3} \mathrm{H}_{3}^{+}$are formed with nearly statistical hydrogen incorporation, indicating a complex mechanism that scrambles all protons. (J Am Soc Mass Spectrom 2004, 15, 114-120) (c) 2004 American Society for Mass Spectrometry
\end{abstract}

$\mathrm{D}$ iacetylene chemistry has drawn attention recently because it is believed that the molecule plays an important role in such diverse areas as planetary atmospheres and combustion processes. Diacetylene has been observed both on one of Saturn's moons, Titan, and on Saturn itself [1-4]. As ozone does on earth, diacetylene protects the lower atmosphere of the moon Titan from ultraviolet radiation from the sun. Diacetylene has been detected in proto-planetary nebula where ionizing UV photons can initiate the formation and buildup of larger organic molecules [5-7]. Diacetylene is also an abundant $\mathrm{C}_{4}$ hydrocarbon found in flames and is involved in several proposed aromatic and polyaromatic hydrocarbon $(\mathrm{PAH})$ forming reactions [8-15]. Pathways for formation of fused aromatic rings in combustion are important to know for the modeling of flames. These PAHs form graphitic structures that are thought to be precursors to soot formation $[9,12]$.

Although no experimental evidence for the formation of aromatic molecules or PAHs in the atmosphere of Titan has been found, the formation of benzene and phenylacetylene in the reaction of metastable diacetylene $\left(\mathrm{C}_{4} \mathrm{H}_{2}^{*}\right)$ with 1,3-butadiene has been reported by Arrington et al. [9]. Corresponding attempts to make PAHs from the reaction of metastable diacetylene with styrene to form naphthalene and naphthalene derivatives proved unsuccessful [11]. However, Bohme and co-workers have shown larger aromatic products in the reaction of neutral diacetylene with benzene and naphthalene radical cation [16].

Published online November 20, 2003

Address reprint request to Dr P. G. Wenthold, Department of Chemistry, Purdue University, 560 Oval Drive, West Lafayette, IN 47907-2084, USA. E-mail: pgw@purdue.edu

${ }^{*}$ Current address: Chemistry Department, Washington University, St. Louis, MO 63130.
The reactions of metastable diacetylene with small organic molecules such as ethylene, acetylene, and propylene have also been investigated in detail $[17,18]$. It has been demonstrated that metastable diacetylene has a rich chemistry with unsaturated hydrocarbons. For example, the dominant product formed from the reaction of metastable diacetylene with ethylene has been characterized as 1-hexene-3,5-diyne [18], whereas reactions with acetylene and propylene result in the formation of triacetylene [17] for the reaction with acetylene, and $\mathrm{C}_{7} \mathrm{H}_{6}$ (either 5-heptene-1,3-diyne or 2-methyl-1-hexene-3,5-diyne), and 1-hexene-3,5-diyne [18] for the reaction with propylene. Although the photochemical reactivity of diacetylene has been explored, little is known about the reactivity of diacetylene radical cation [19], which is also likely present in planetary nebulae [7] and combustion systems [12].

Changes in electronic and thermodynamic properties caused by ionization can often lead to reactivity in radical cations that is dramatically different from that of the corresponding neutral molecules. However, it is sometimes found that radical cation chemistry can mirror the photochemistry of the system because photochemical excitation leads to the formation of a "hole" similar to that in the radical cation. A classic example of radical cation reactivity that reflects photochemistry is the McLafferty rearrangement, which is a radical cation equivalent of a Norrish Type II reaction [20-23].

In this work, we have examined the reactivity of the diacetylene radical cation with ethylene in order to compare it with the photochemical results. The reaction products, $\mathrm{C}_{6} \mathrm{H}_{6}^{+}, \mathrm{C}_{4} \mathrm{H}_{4}^{+}$, and $\mathrm{C}_{3} \mathrm{H}_{3}^{+}$, formed in the reaction have been investigated by using ion-molecule reactions, collision induced dissociation (CID), energy resolved mass spectrometry, and isotopic labeling. Unlike what was formed in the neutral photochemistry, the addition of diacetylene radical cation to ethylene 
leads to the formation of the aromatic product, benzene. This is the first example of diacetylene radical cation undergoing an aromatic ring formation reaction. Isotopic labeling studies suggest that the reaction of diacetylene cation with ethylene occurs by a complex mechanism involving significant hydrogen scrambling.

\section{Experimental}

All experiments were carried out at room temperature (298 $\pm 2 \mathrm{~K})$ with a flowing afterglow-triple quadrupole mass spectrometer that has been described previously [24]. Diacetylene radical cations were generated in the $1 \mathrm{~m} \times 7.3 \mathrm{~cm}$ helium flow reactor $(\mathrm{P}[\mathrm{He}]=0.400$ torr, flow $[\mathrm{He}]=200 \mathrm{std} \mathrm{cc} / \mathrm{s}$ ) by electron impact ionization (EI) of neutral diacetylene. The results obtained from ions generated by charge transfer chemical ionization with acetaldehyde are indistinguishable from those obtained with ions formed by EI. Ion-molecule reactions are carried out by adding neutral reagent vapors through any of a number of inlets along the length of the flow tube. Reaction rates are measured by monitoring the yield of reactant ion as a function of neutral flow, where the neutral reagent is added through one of two ring inlets [24]. The efficiency, eff, of the reaction is obtained by comparing the measured rate constant for the reaction with the collision rate coefficient, calculated by using parameterized trajectory theory [25], with eff $=k / k_{\text {coll }}$. The ions in the flow tube are thermalized to ambient temperature by ca. $10^{5}$ collisions with the helium buffer gas, and then extracted from the flow tube through a $1 \mathrm{~mm}$ orifice and focused into the low pressure EXTREL triple quadrupole analyzer (Pittsburgh, PA).

Ions can be mass analyzed with either the first (Q1) or third (Q3) quadrupole, or can be subjected to MS/MS experiments, wherein the ions with a desired mass-tocharge ratio are selected in Q1 and allowed to collide with a neutral target in the second quadrupole, Q2. Energy resolved mass spectra are obtained by monitoring product formation while the energy of the Q2 rod offset is scanned. The reactant and product ions are extracted into Q3 and detected with an electron multiplier operating in pulse-counting mode.

All chemicals were obtained commercially except for diacetylene, which was synthesized by Zwier and coworkers at Purdue University in a dilute gas-phase mixture of helium (1-5\% diacetylene) using a procedure described elsewhere [26].

\section{Results and Discussion}

\section{Reaction of Diacetylene Radical Cation with Ethylene}

As part of our studies of pericyclic reactions of organic ions [27, 28], the principle aims of this study are to investigate if the gas-phase reaction takes place between diacetylene radical cation and ethylene, and if so,

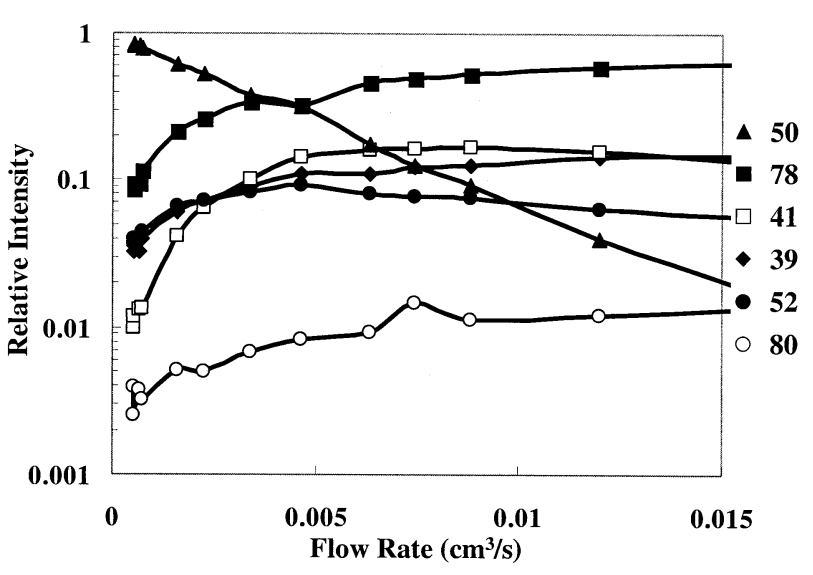

Figure 1. Relative intensities for the reaction of $\mathrm{C}_{4} \mathrm{H}_{2}^{+}$with ethylene as a function of ethylene flow rate in the flow tube.

to characterize the products formed. The diacetylene radical cation does react with ethylene added downstream in the flow tube, with an apparent bimolecular rate constant of $1.3 \pm 0.3 \times 10^{-9} \mathrm{~cm}^{3}$ molecule ${ }^{-1} \mathrm{~s}^{-1}$ (eff $=85 \%$ ) at a He pressure of 0.400 torr. A plot of the reactant and product intensity as a function of the ethylene flow rate is shown in Figure 1. The observed primary products of the reaction at this pressure include an adduct ion at $m / z 78$, and products at $m / z$ 52 and 39 (eq 1). In the flow tube, the $m / z 78,52$, and 39 products are formed in the relative yields of $79 \%$ $m / z 52,4 \% m / z 39$, and $17 \% m / z 78$ at a He pressure of 0.400 torr. Additional products are observed at $m / z 41$ and 80 , but their intensities are negligible in the limit of zero reactant flow. Whereas the product at $\mathrm{m} / \mathrm{z} 80$ is a secondary product, the $m / z 41$ product is either a secondary or otherwise very minor product and has not been considered further. Experiments with mass selected $\mathrm{C}_{4} \mathrm{H}_{2}^{+}$in Q2 give a branching ratio in Q2 of $64 \% / 20 \% / 16 \%$ for $m / z 52,39$, and 78 , respectively. Surprisingly, the fraction of $m / z 78$ measured at the limit of zero pressure in Q2 $(16 \%)$ is basically the same as the value of $17 \%$ measured at 0.400 torr in the flowing afterglow, indicating that a significant amount of adduct lives long enough to be detected before dissociating [29-31].

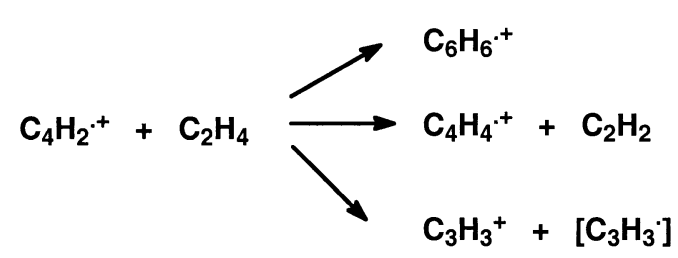

The products of the radical cation reaction differ from those formed in the reaction of metastable diacetylene with ethylene, where the dominant product has been identified as 1-hexene-3,5-diyne [18], resulting 
from addition and loss of $\mathrm{H}_{2}$. The corresponding cation $\mathrm{C}_{6} \mathrm{H}_{4}^{+}$is not observed in the reaction of diacetylene cation with ethylene.

\section{Product Identification}

The structure of the $\mathrm{m} / \mathrm{z} 78$ product was determined to be that of benzene radical cation by using the ionmolecule reaction with 2-iodopropane. Gross and coworkers have shown that benzene cation reacts with 2-iodopropane by 2-propyl radical abstraction (eq 2) [32].

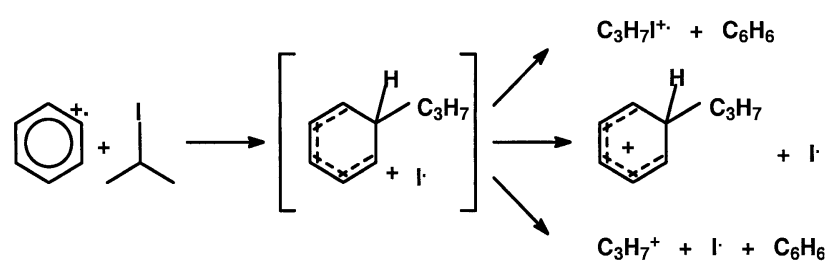

The $m / z 78$ ion formed in the reaction of diacetylene cation with ethylene reacts almost completely with 2-iodopropane in the flow tube to form the product, $\mathrm{m} / \mathrm{z}$ 121, characteristic of benzene cation reactivity. The $\mathrm{C}_{3} \mathrm{H}_{7} \mathrm{I}^{++}$and $\mathrm{C}_{3} \mathrm{H}_{7}^{+}$cations are also formed when 2-iodopropane is added to the flow tube, but their formation is not necessarily due to charge transfer with the adduct ion as it could result from reaction with other ions present.

The reaction of the mass selected adduct ion with 2-iodopropane was also carried out in the gas-tight, rf-only quadrupole (Q2) under low energy conditions. The mass spectra of the reaction products taken at an energy of $0.3 \mathrm{eV}(\mathrm{lab})$, are illustrated in Figure $2 \mathrm{a}$ and $\mathrm{b}$. Three major products were observed at $\mathrm{m} / \mathrm{z} 43,121$, and 170 , corresponding to $\mathrm{C}_{3} \mathrm{H}_{7}^{+}, \mathrm{C}_{9} \mathrm{H}_{13}^{+}$, and $\mathrm{C}_{3} \mathrm{H}_{7} \mathrm{I}^{+}$, respectively. Although the formation of $\mathrm{C}_{3} \mathrm{H}_{7}^{+}$and $\mathrm{I}$ in the reaction is slightly endothermic [33], it is promoted by the favorable entropy change. $\mathrm{The}_{3} \mathrm{C}_{3} \mathrm{H}_{7}^{+}$ion is the most abundant product, and the $\mathrm{C}_{9} \mathrm{H}_{13}^{+}$and $\mathrm{C}_{3} \mathrm{H}_{7} \mathrm{I}^{++}$products are formed in relative yields of $0.47 \pm 0.05$ and $0.70 \pm$ 0.05 , respectively. The same products are observed with benzene radical cation under the same conditions, in relative yields of $1.0: 0.41: 0.74$. Given that the uncertainties in the relative yields are also approximately \pm 0.05 , the intensities are indistinguishable. The agreement of the relative intensities of the three product ions from the reaction of the adduct ion and benzene cations with 2-iodopropane is consistent with the proposal that the adduct ion has the benzene structure.

Final confirmation of the adduct ion structure was carried out by using energy resolved mass spectrometry. Because different ion isomers have different energetic and dynamic requirements for product formation, the energy dependence of product formation can

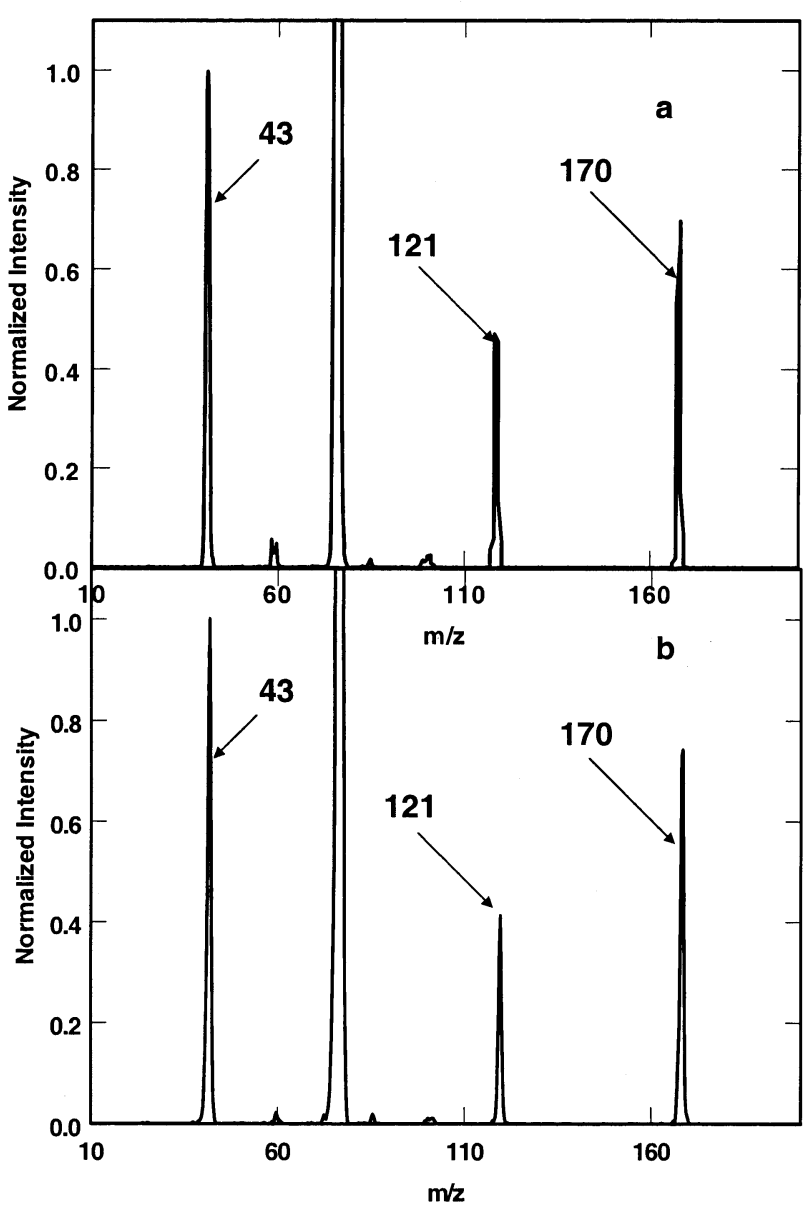

Figure 2. Mass spectra of the products formed in the ionmolecule reaction of $\mathrm{C}_{6} \mathrm{H}_{6}^{++}$ions with 2-iodopropane in Q2. (a) Diacetylene cation/ethylene adduct; (b) ionized benzene.

be used to identify ion structures in reactions in which the products and their relative yields at a single energy are coincidentally the same [27, 28]. Ion structures can be determined by comparing the shapes of the appearance curves for the reaction products for the unknown with those of authentically prepared ions. In this work, we compare the shapes of the appearance curves for formation of $\mathrm{m} / \mathrm{z} 43,121$, and 170 from the reaction of 2-iodopropane with the adduct with those obtained from the reaction of authentically prepared benzene radical cations.

The normalized appearance curves for the formation of the three product ions from the reaction of $\mathrm{m} / \mathrm{z} 78$ with 2-iodopropane are shown in the left half of Figure $3 a, b$, and c. Figure $3 a$ shows the appearance curves for the formation of $m / z 43$ ions, whereas Figure $3 b$ and c show the appearance curves for the formation of $\mathrm{m} / \mathrm{z}$ 121 and 170, respectively. The appearance curves for the three products obtained for the adduct ion (shown as squares) are indistinguishable from those for benzene radical cation (shown as circles), measured on the same day under identical instrumental conditions. The agreement between the shapes of the appearance curves for 

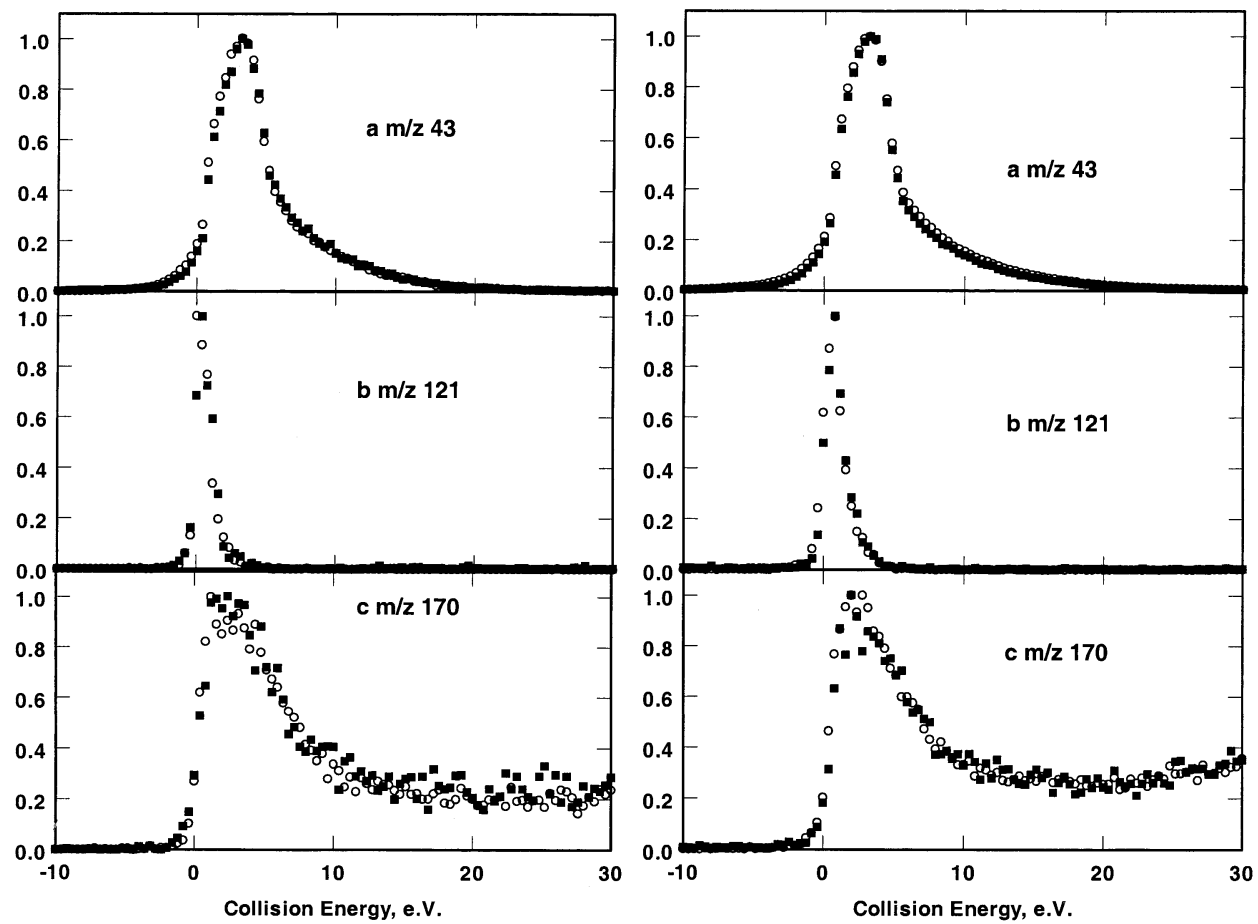

Figure 3. Energy resolved mass spectra of (a) $\mathrm{m} / \mathrm{z} 43$, (b) $\mathrm{m} / \mathrm{z} 121$, and (c) $\mathrm{m} / \mathrm{z}$ 170, formed in the reaction of $\mathrm{C}_{6} \mathrm{H}_{6}^{++}$ions with 2-iodopropane. Benzene radical cation data are shown as circles. The data shown as squares in the left half of the figure are for the adduct formed in the reaction of diacetylene cation with ethylene. The data shown as squares in the right half of the figure are for ionized 1,5-hexadiyne.

the three products rules out the possibility of coincidental agreement of the CID spectra, confirming that the adduct ion has the same structure as benzene radical cation.

Similar energy-resolved studies of the 2-iodopropane reaction have been repeated with other $\mathrm{C}_{6} \mathrm{H}_{6}^{+}$ isomers in order to ascertain its utility in determining ion structure. One example is ionized 1,5-hexadiyne, which was subjected to ion-molecule reactions in Q2 under the same conditions used for the reaction of the benzene and adduct ions. Again, products were found at $m / z 43,121$, and 170, with the same energy dependences that were observed for benzene (right half of Figure $3 a, b$, and c). This is consistent with previous proposals that ionized 1,5-hexadiyne rearranges to the benzene cation structure with a small barrier [34-38].

For comparison, the reaction of ionized 2,4hexadiyne with 2-iodopropane in Q2 was carried out. Gross and co-workers have suggested previously that ionized 2,4-hexadiyne radical cation does not rearrange to benzene cation [32]. Indeed, the spectrum for reaction of this $\mathrm{C}_{6} \mathrm{H}_{6}^{-+}$isomer has products at $m / z 43$ and 93 , and the $m / z 121$ ion is not observed at all. Thus, significant differences are observed between products in this reaction and those for benzene cation, consistent with the findings of Gross and co-workers that ionized 2,4hexadiyne does not rearrange to a benzene structure.

\section{Isotopic Labeling Experiments}

The other products formed in the reaction of diacetylene cation with ethylene are $\mathrm{m} / \mathrm{z} 52$ and $\mathrm{m} / \mathrm{z}$ 39. The product at $m / z 52$ is presumably the vinyl acetylene or methylene cyclopropene radical cation [39-41]. Potential pathways for the formation of this ion could include $\mathrm{H}_{2}$ abstraction from $\mathrm{C}_{2} \mathrm{H}_{4}$ or a more complicated addition/rearrangement/elimination pathway involving one or more intermediates. To investigate the mechanism of $\mathrm{m} / \mathrm{z} 52$ formation, we examined the reaction of diacetylene cation with deuterated ethylene, $\mathrm{C}_{2} \mathrm{D}_{4}$, at low energy conditions $(<1 \mathrm{eV})$ in Q2. Relative peak intensities were measured at several pressures and extrapolated to zero pressure. The measured ratio of di, tri, and tetradeuterated product is 5:7:1, which is in excellent agreement with a purely statistical distribution of $6: 8: 1$. Thus, $m / z 52$ is likely formed by a mechanism that allows nearly complete scrambling of all the hydrogen atoms. Given that $m / z 52$ is a CID product observed from benzene cation, it is tempting to propose that $m / z 52$ formed in the reaction results from benzene cation that dissociates before it can be cooled by collisions with the He buffer. However, the cross section for $\mathrm{C}_{4} \mathrm{H}_{4}^{++}$formation upon CID of benzene cation $\left(0.3 \AA^{2}\right.$ at a collision energy of $13 \mathrm{eV}$ center-of-mass) appears to be too low to account for the efficient formation of $\mathrm{C}_{4} \mathrm{H}_{4}^{++}$ in the reaction. The $\mathrm{C}_{4} \mathrm{H}_{4}^{++}$product could also be formed 
from an acyclic intermediate wherein all hydrogen atoms are scrambled. An essentially statistical mixture of deuterium incorporation $(1: 3: 1$ for $m / z 40,41$, and 42 ) is also observed for the $\mathrm{C}_{3} \mathrm{H}_{3}^{+}$cation, indicating that it too is formed by complex rearrangement. Both $\mathrm{C}_{4} \mathrm{H}_{4}^{++}$ and $\mathrm{C}_{3} \mathrm{H}_{3}^{+}$are commonly observed fragments in mass spectra of $\mathrm{C}_{6} \mathrm{H}_{6}$ isomers [42] and therefore do not provide much information about the structure of the intermediate in the reaction. Recent computational studies $[43,44]$ for the formation of cyclohexene in the reaction of butadiene radical cation with ethylene predict a stepwise mechanism wherein the initial step is addition to create a linear distonic cation. If the same process occurs in the reaction of ethylene with diacetylene cation, the initial intermediate would be a distonic radical cation as shown in eq 3 , which could either first cyclize to 1,2,3-cyclohexatriene radical cation and then rearrange to benzene (eq 3a), or could undergo hydrogen scrambling to generate another acyclic structure, such as a hexadienyne, that is capable of rearranging to benzene cation (eq 3b) [32]. The fact that the reaction of butadiene radical cation with ethylene leads to formation of an acyclic product [28] favors a pathway like that in eq $3 b$.

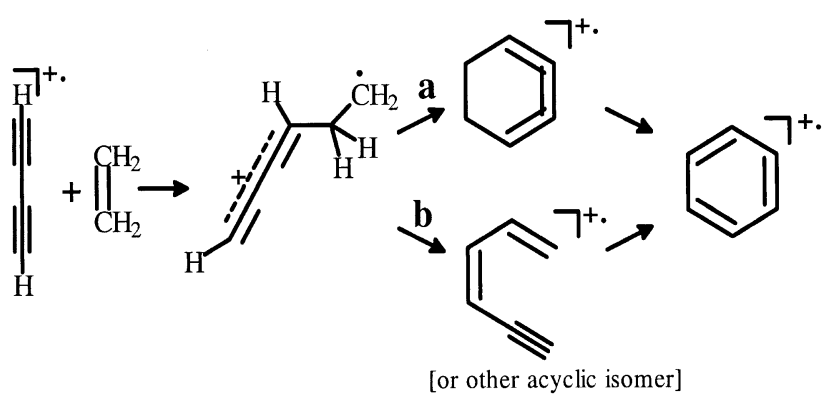

\section{Comparison of Ion Chemistry and Neutral Photochemistry}

Thermal and energy-resolved ion molecule reactions show that the adduct ion formed from the reaction of diacetylene radical cation with ethylene in a flowing afterglow mass spectrometer is the benzene radical cation. The formation of benzene in the course of the reaction is not surprising because it is the thermodynamically favored product (Table 1) [32]. Although aromatic ring formation has been observed previously in the reaction of metastable diacetylene with 1,3butadiene [9], the photochemical reaction of diacetylene with ethylene gives nonaromatic products identified as $\mathrm{C}_{6} \mathrm{H}_{4}$ and $\mathrm{C}_{6} \mathrm{H}_{5}$ [18]. Therefore, photochemical results do not mirror the radical cation chemistry. It should be noted that whereas the ion/molecule reactions were carried out at high pressure, the photochemical reactions were carried out at low pressures where adduct is less likely to be observed. However, even after taking
Table 1. Heats of formation of various $\mathrm{C}_{6} \mathrm{H}_{6}^{++}$isomers ${ }^{\mathrm{a}}$

\begin{tabular}{lc}
\hline $\mathrm{C}_{6} \mathrm{H}_{6}{ }^{-+}$isomer & $\Delta H_{f}$ \\
\hline \hline Benzene & 233 \\
Fulvene & 240 \\
3,4-Dimethylenecyclobutene & 283 \\
1,2,4,5-Hexatetraene & 296 \\
Dewar Benzene & 300 \\
1,3-Hexadiyne & 307 \\
1,3-Hexadien-5-yne & 307 \\
1,2-Hexadien-5-yne & 316 \\
1,4-Hexadiyne & 319 \\
1,5-Hexadiyne & 330 \\
\hline
\end{tabular}

aValues in $\mathrm{kcal} / \mathrm{mol}$, from reference [32]

this into account we find that the reaction products, $\mathrm{C}_{4} \mathrm{H}_{4}^{++}$and $\mathrm{C}_{3} \mathrm{H}_{3}^{+}$, do not agree with those found in the photochemical reactions. In addition, the photochemical reaction of diacetylene with deuterated ethylene does not occur with scrambling of hydrogens, as is observed in the radical cation reaction, as the predominant product is $\mathrm{C}_{6} \mathrm{HD}_{3}$, indicating loss of one hydrogen from diacetylene and one from ethylene.

The differences in the isotopic distributions for the reactions with $\mathrm{C}_{2} \mathrm{D}_{4}$ highlight an important difference between the photochemistry and radical cation chemistry. Barriers for hydrogen shifting in open-shell (photochemical) intermediates are typically much higher than those in radical cations [45], and these energybarrier differences may lead to differences in reactivity. Thus, whereas the photochemical/radical cation comparison is valid in many cases, there are still many electronic differences that can lead to very different chemical results.

\section{Acknowledgments}

The authors thank Professor Tim Zwier and co-workers for providing the diacetylene used in this experiment, and for valuable discussions. This work was supported by the National Science Foundation (CHE-0137627). The authors also thank the donors of the Petroleum Research Fund, administered by the American Chemical Society, for additional support. Lastly, they thank Professor Michael Gross for useful suggestions regarding this work.

\section{References}

1. Kunde, V. J.; Aiken, A. C.; Hane, R. A.; Jennings, D. E.; Maguire, W. C.; Samuelson, R. E. $\mathrm{C}_{4} \mathrm{H}_{2}, \mathrm{HC}_{3} \mathrm{~N}$, and $\mathrm{C}_{2} \mathrm{~N}_{2}$ in Titan's Atmosphere. Nature 1981, 292, 686.

2. Coustenis, A.; Bezard, B.; Gautier, D.; Marten, A.; Samuelson, R. Titan's Atmosphere from Voyager Infrared Observations. III. Vertical Distributions of Hydrocarbons and Nitriles Near Titan's North Pole. Icarus 1991, 89, 152.

3. Coustenis, A.; Bezard, B.; Gautier, D. Titan's Atmosphere from Voyager Infrared Observations. I. The Gas Composition of Titan's Equitorial Region. Icarus 1991, 80, 54.

4. Graauw, T. D.; Feuchtgruber, H.; Bezard, B.; Drossart, P.; Encrenaz, T.; Beintema, D. A.; Griffen, M.; Heras, A.; Kessler, M.; Leech, K.; Lellouch, E.; Morris, P.; Roelfsema, P. R.; Roos-Serote, M.; Salama, A.; Vandenbussche, B.; Valentijn, 
E. A.; Davis, G. R.; Naylor, D. A. First Results of ISO-SWS Observations of Saturn. Detection of $\mathrm{CO}_{2}, \mathrm{CH}_{3} \mathrm{C}_{2} \mathrm{H}, \mathrm{C}_{4} \mathrm{H}_{2}$, and Tropospheric $\mathrm{H}_{2} \mathrm{O}$. Astronom. Astrophys. 1997, 321, L13.

5. Doty, S. D.; Leung, C. M. Detailed Chemical Modeling of the Circumstellar Envelopes of Carbon Stars. Application to IRC +10216. Astrophys. J. 1998, 502, 898.

6. McCarthy, M. C.; Travers, M. J.; Chen, W.; Gottlieb, C. A.; Thaddeus, P. Laboratory Detection of the Carbon Ring Chain $\mathrm{C}_{9} \mathrm{H}_{2}$. Astrophys. J. 1998, 498, L89.

7. Cernicharo, J.; Heras, A. M.; Tielens, A. G. G. M.; Pardo, J. R.; Herpin, F.; Guelin, M.; Waters, L. B. F. M. Infrared Space Observatory's Discovery of $\mathrm{C}_{4} \mathrm{H}_{2}, \mathrm{C}_{6} \mathrm{H}_{2}$, and Benzene in CRL 618. Astrophys. J. 2001, 546, L123.

8. McEnally, C. S.; Pfefferle, L. D.; Mohammed, R. K.; Smooke, M. D.; Colket, M. B. Mapping of Trace Hydrocarbon Concentrations in Two-Dimensional Flames Using Single-Photon Photoionization Mass Spectrometry. Anal. Chem. 1999, 71, 364.

9. Arrington, C. A.; Ramos, C.; Robinson, A. D.; Zwier, T. S. Aromatic Ring-Forming Reactions of Metastable Diacetylene with 1,3-Butadiene. J. Phys. Chem. A 1998, 102, 3315.

10. Robinson, A. G.; Winter, P. R.; Ramos, C.; Zwier, T. S. Ultraviolet Photochemistry of Diacetylene: Reactions with Benzene and Toluene. J. Phys. Chem. A 2000, 104, 10312.

11. Robinson, A. G.; Winter, P. R.; Zwier, T. S. The Ultraviolet Photochemistry of Diacetylene with Styrene. J. Phys. Chem. A 2002, 106, 5789 .

12. Fialkov, A. B. Investigations on Ions in Flames. Prog. Energy Combust. Sci. 1997, 23, 399.

13. Lamprecht, A.; Atakan, B.; Kohse-Hoeinghaus, K. Fuel-Rich Propene and Acetylene Flames: A Comparison of Their Flame Chemistries. Combust. Flame 2000, 122, 483.

14. Doute, C.; Delfau, J.-L.; Vovelle, C. Reaction Mechanism for Aromatics Formation in a Low Pressure, Premixed AcetyleneOxygen/Argon Flame. Combust. Sci. Technol. 1994, 103, 153.

15. Hai, W.; Frenklach, M. A Detailed Kinetic Modeling Study of Aromatics Formation in Laminar Premixed Acetylene and Ethylene Flames. Combust. Flame 1997, 110, 173.

16. Bohme, D. K.; Wlodek, S.; Zimmerman, J. A.; Eyler, J. R. Formation of $\mathrm{C}_{10} \mathrm{H}_{8}^{+}$from the Benzene Radical Cation: A Case for the Growth of Polycyclic Aromatic Hydrocarbon Ions by Ion-Molecule Reactions in the Gas Phase? Int. J. Mass Spectrom. Ion Processes 1991, 109, 31.

17. Frost, R. K.; Zavarin, G.; Zwier, T. S. Ultraviolet Photochemistry of Diacetylene: Metastable $\mathrm{C}_{4} \mathrm{H}_{2}+\mathrm{C}_{2} \mathrm{H}_{2}$ Reaction in Helium and Nitrogen. J. Phys. Chem. 1995, 99, 9408.

18. Frost, R. K.; Arrington, C. A.; Ramos, C.; Zwier, T. S. Ultraviolet Photochemistry of Diacetylene: The Metastable $\mathrm{C}_{4} \mathrm{H}_{2}^{*}$ Reaction with Ethene, Propene, and Propyne. J. Am. Chem. Soc. 1996, 118, 4451.

19. Dheandhanoo, S.; Forte, L.; Fox, A.; Bohme, D.K. Ion-Molecule Reactions with Carbon Chain Molecules: Reactions with Diacetylene and the Diacetylene Cation. Can. J. Chem. 1986, 64, 641.

20. Vedernikova, I.; Claeys, M.; Salahub, D. R.; Casida, M. E. Excitation Processes in Alkali-Cationized Esters: A Molecular Orbital Study. Int. J. Mass Spectrom. 2001, 210/211, 21.

21. Dorigo, A. E.; McCarrick, M. A.; Loncharich, R. J.; Houk, K. N. Transition Structures for Hydrogen Atom Transfers to Oxygen. Comparisons of Intermolecular and Intramolecular Processes and Open- and Closed-Shell Systems. J. Am. Chem. Soc. 1990, 112, 7508.

22. De Feyter, S.; Diau, E. W.-G.; Zewail, A. H. Femtosecond Dynamics of Norrish Type-II Reactions: Nonconcerted Hydrogen-Transfer and Diradical Intermediacy. Angew. Chem. Int. Ed. 2000, 39, 260.
23. Gooden, R.; Brauman, J. I. Photodissociation of Butyrophenone Cation. Ionic Analogs of Norrish Type I and II Reactions. J. Am. Chem. Soc. 1977, 99, 1977.

24. Marinelli, P. J.; Paulino, J. A.; Sunderlin, L. S.; Wenthold, P. G.; Poutsma, J. C.; Squires, R. R. A Tandem Selected Ion Flow Tube-Triple Quadrupole Instrument. Int. J. Mass Spectrom. Ion Processes 1994, 130, 89.

25. Su, T.; Chesnavich, W. J. Parameterization of the Ion-Polar Molecule Collision Rate Constant by Trajectory Calculations. J. Chem. Phys. 1982, 76, 5183.

26. Armitage, J. B.; Jones, E. R. H.; Whiting, M. C. Researches on Acetylenic Compounds. Part XXXVII. The Synthesis of Conjugated Tetra-Acetylenic Compounds. J. Chem. Soc. 1952, 2014.

27. Hu, H.; Wenthold, P. G. The Stucture of Ionized 1,5 Hexadiene in the Gas Phase. J. Am. Soc. Mass Spectrom. 2001, 12, 840.

28. Hu, H.; Wenthold, P. G. Reaction of the Butadiene Cation with Ethylene in the Gas Phase. J. Phys. Chem. A 2002, 106, 10550.

29. Allen, W. N.; Lampe, F. W. Ion-Molecule Reactions in Monosilane-Benzene Mixtures. Long-Lived Collision Complexes. J. Am. Chem. Soc. 1977, 99, 2943.

30. Schelling, F. J.; Castleman, A. W. A Classical Trajectory Study of the Angular Momentum Coupling Model. The Influence of Anisotropic Polarizability on the Lifetimes of Complexes Formed in Ion-Molecule Collisions. Chem. Phys. Lett. 1984, 111, 47.

31. Green, R. J.; Kim, H.-T.; Qian, J.; Anderson, S. L. Complex Formation, Rearrangement, and Reaction in $\mathrm{PhOH}^{+}+\mathrm{ND}_{3}$ : Vibrational Mode Effects, Recoil Velocities, and ab Initio Studies. J. Chem. Phys. 2000, 113, 4158.

32. Gross, M. L.; Russell, D. H.; Aerni, R. J.; Bronczyk, S. A. Ion-Molecule Reaction Chemistry of Various Gas-Phase $\mathrm{C}_{6} \mathrm{H}_{6}$ Radical Cations. J. Am. Chem. Soc. 1977, 99, 3603.

33. Lias, S. G.; Bartmess, J. E.; Liebman, J. F.; Holmes, J. L.; Levin, R. D.; Mallard, W. G. "Ion Energetics Data" in NIST Chemistry WebBook, NIST Standard Reference Database Number 69, Linstrom, P.J.; Mallard, W. G., Eds., March 2003, National Institute of Standards and Technology, Gaithersburg MD, 20899. (http://webbook.nist.gov).

34. van der Hart, W. J. Ab Initio Calculations on the Isomerization of the 1,5-Hexadiyne Radical Cation. J. Am. Soc. Mass Spectrom $1997,8,599$.

35. van de Guchte, W. J.; van der Hart, W. J.; de Koning, L. J.; Nibbering, N. M. M.; Dunbar, R. C. Formation of Long-Lived Benzene Ions During Charge Exchange Ionization of 1,5Hexadiyne in an Ion Cyclotron Resonance Spectrometer. Int. J. Mass Spectrom. Ion Processes 1993, 123, 11.

36. Dymerski, P. P.; Harrison, A. G. A Time-Resolved Study of the Unimolecular Fragmentaion of Some $\mathrm{C}_{6} \mathrm{H}_{6}^{++}$Molecular Ions. J. Phys. Chem. 1976, 80, 2825.

37. van der Hart, W. J. The Isomerization of $\mathrm{C}_{6} \mathrm{H}_{6}$ Radical Cations. A Comparison of Photodissociation Results with Semi-Emperical Molecular Orbital Calculations. Int. J. Mass Spectrom. Ion Processes 1994, 130, 173.

38. Lifshitz, C.; Ohmichi, N. Time-Dependent Mass Spectra and Breakdown Graphs. 13. Time-Resolved Photoionization Mass Spectrometry of 1,5-Hexadiyne. J. Phys. Chem. 1989, 93, 6329 .

39. van der Hart, W. J. Ab Initio Calculations on the Isomerization of Benzene Radical Cation to the Dewar Benzene Structure and on Possible Pathways for the Formation of $\mathrm{C}_{4} \mathrm{H}_{4}$ Fragment Ions From the Benzene Radical Cation. Int. J. Mass Spectrom. 1998, 176, 23.

40. Zhang, M.-Y.; Carpenter, B. K.; McLafferty, F. W. Gas-Phase Formation of Four Isomeric $\mathrm{C}_{4} \mathrm{H}_{4}^{++}$Ions. Ionic Isomer Quantitation with Neutral-Reionization Mass Spectrometry. J. Am. Chem. Soc. 1991, 113, 9499. 
41. Shay, B. J.; Eberlin, M. N.; Cooks, R. G.; Wesdemiotis, C. Ion-Molecule Reactions and Collision-Activated Dissociation of $\mathrm{C}_{4} \mathrm{H}_{4}^{+}$Isomers: A Case Study in the Use of the $\mathrm{MS}^{3}$ Capabilities of a Pentaquadrupole Mass Spectrometer. J. Am. Soc. Mass Spectrom. 1992, 3, 518.

42. Stenhagen, E.; Abrahamsson, S.; McLafferty, F. W. Atlas of Mass Spectral Data, Vol. I; Interscience Publishers: New York, 1969, p. 101.
43. Hofmann, M.; Schaefer, H. F. Pathways for the Reaction of the Butadiene Radical Cation, $\left[\mathrm{C}_{4} \mathrm{H}_{6}\right]^{+}$, with Ethylene. J. Phys. Chem. A 1999, 103, 8895.

44. Haberl, U.; Wiest, O.; Steckhan, E. Ab Initio Studies of the Radical Cation Diels-Alder Reaction. J. Am. Chem. Soc. 1999, 121, 6730.

45. Baker, J. On the Stability of the Vinylidene Radical Cation. Chem. Phys. Lett. 1989, 159, 447. 